\title{
Video games Squared. Espacios heterotópicos y videojuegos en la era del audiovisual
}

\author{
Eduardo Barros Grela, Pablo Cancelo López, Marco Vé- \\ lez Barreiro \\ Universidade da Coruña
}

ebarros@udc.es, pcancelo@udc.es, marcovelez@edu.xunta.es

https://dx.doi.org/10.12795/futhark.2013.i08.02

\begin{abstract}
Resumen: La paradigmática consolidación del software de entretenimiento en el siglo XXI y el desarrollo de la tecnología - y de la industria- en el ámbito de los videojuegos ha dado lugar a nuevas formas de narración que implican una nueva conceptualización de la cultura y de los esquemas literarios tradicionales.

En este artículo se propone una aproximación crítica al estudio de los videojuegos como elementos discursivos con una narratividad propia, y se formula una metodología basada en un triple enfoque: una reflexión teórica sobre la problemática actual del formato digital del videojuego como narrativa; una contextualización histórica del desarrollo del videojuego desde sus inicios hasta la actualidad; y un enfoque analítico que estudia la aplicabilidad de las reflexiones teóricas sobre el videojuego aplicadas al ámbito de la pedagogía. Palabras clave: Videojuegos, narrativas digitales, cultura popular, nuevas tecnologías, pedagogía.
\end{abstract}

Abstract: The paradigmatic consolidation of the entertainment software in the twenty-first century, as well as its technological —and industrial- development in the field of video games has given rise to new narrative forms involving a new conceptualization of culture and traditional literary schemes. This article poses a critical approach to the study of videogames as discursive elements that possess their own narrative forms. The methodology we formulate is based on a threefold approach: first, we provide a theoretical observation of the current problems of video games as digital narratives; then we look at the historical context of the development of video games from its beginnings to the present. Finally, this article delivers an analytical 
approach to the applicability of those theoretical and historical characteristics of the video game applied to the field of pedagogy.

Palabras clave: Video game, digital narratives, popular culture, new technologies, pedagogy.

Este artículo pretende ofrecer una panorámica teórica, histórica y de aplicación de los videojuegos como elementos discursivos cuya narratividad ha de ser equiparable a la que tradicionalmente ha venido ocupando los espacios de discusión académica para la literatura o el cine. Esa observación de la narratividad en el videojuego ha de ser sometida a un triple enfoque - que en este artículo se intenta reproducir- fundamentado en las diferentes perspectivas analíticas que ofrece. El primero de estos enfoques es el que se detiene en las reflexiones teóricas necesarias para introducir la problemática actual de un formato digital de tanta controversia como la del videojuego. Vilipendiado por unos pedagogos, críticos de la estética tradicional, moralistas, etc- y aplaudido por otros —eminentemente, jugadores-, el videojuego ha empezado a hacerse un hueco en los centros de enseñanza superior como disciplina de estudio (a través del peso específico que los Estudios Culturales han venido adquiriendo), e incluso como carrera universitaria propia (lo cual suele ser un antecedente de su legitimación social). En esta "disciplina" de reciente creación (Video Game Studies) confluyen diferentes aproximaciones críticas que intentar abarcar el mayor recorrido posible de la culturalidad a partir del discurso digital del videojuego: estudios de sociología, de antropología, de filosofía, de teoría cultural, etc. La primera parte de este estudio intentará, por lo tanto, ahondar en algunas de las ramificaciones de esta última aproximación crítica, en concreto, en las que tienen que ver con el estudio de la narratividad, también como espacio ontológico.

Tras situar el panorama teórico que conlleva la interrogación crítica de la discursividad del videojuego, el segundo enfoque analítico propuesto en este estudio es el que traza una contextualización histórica del desarrollo del videojuego desde sus inicios hasta la actualidad (entendiendo "actualidad" no tanto como el momento presente, sino como el de las manifestaciones digitales que están por venir en un futuro a corto plazo). Tal contextualización se plantea desde una lectura del videojuego como mecanismo resultante de una actuación doble: la que incide sobre su desarrollo temático, y la que subraya el desarrollo técni$\mathrm{co}^{1}$. La complejidad narratológica de, por ejemplo, Heavy Rain (2010), que incluye digresiones, historias paralelas, retrospecciones, etc. no

1 Francisco García García, "Videojuegos y Virtualidad Narrativa” Icono 14, Revista de Comunicación y Nuevas Tecnologías, 8: 2006 (1-24).

Futhark 8 (2013) Barros, Vídeo games Squared, 31-54

ISSN 1886-9300 
podría ser posible sin una complejidad técnica paralela cuyos recursos visuales permitan trasladar fehacientemente al jugador alheterotópico-espacio al que hacen referencia. Tampoco la capacidad de interactuar socialmente con otros usuarios a través de la red y por medio de avatares configurados a imagen y semejanza-o no-de los jugadores podría haber sido posible en la forma en la que lo es en la actualidad, desde luego, a mediados de los años ochenta. Un repaso por los momentos más significativos en cuanto al desarrollo técnico y narrativo de los videojuegos es, por lo tanto, esencial para completar una panorámica exhaustiva de estos nuevos soportes discursivos, y así se lleva a cabo en la segunda parte de este estudio.

Para terminar, el tercer enfoque analítico que se propone es el que necesita todo estudio científico para legitimar sus presupuestos: la aplicabilidad de sus reflexiones teóricas. De nuevo, un gran abanico de posibilidades se abre para habilitar un espacio de funcionalidad del contexto teórico narrativo del videojuego. En este caso, el ámbito escogido ha sido el de la pedagogía. En un tiempo en el que las nuevas generaciones poseen, mayoritariamente, un nivel de alfabetización tecnológica muy superior al de sus educadores, y en el que el contacto con la cultura visual es declaradamente hegemónico, se impone el imperativo pedagógico de transmitir conocimientos por medio de una utilización sensata de los canales que los alumnos no solo dominan, sino a los que también les son inherentes. Resulta necesario, además, trascender esa obligatoriedad curricular de utilizar la tecnología en el aula, ya que, mal usada, ésta puede ser perjudicial para los fines didácticos que se planteen. En lugar de adaptar la tecnología a los métodos tradicionales de enseñanza (utilizar software de presentaciones para leer palabra por palabra lo que aparece escrito en la proyección, por ejemplo), los recursos tecnológicos han de estar dirigidos a establecer lazos comunicativos con el alumnado, utilizando siempre el lenguaje que éste mejor entienda y maneje. En el caso que ofrece este artículo, conseguir adaptar la "jugabilidad" del videojuego a las necesidades pedagógicas del aula se presenta como una acción de múltiples posibilidades, y se parte de una presentación ante el alumnado que es, en naturaleza, garante del éxito motivacional ante el que tantas otras han fracasado.

Con todo ello, este estudio propone desemantizar la negativa connotación académica en vigencia del videojuego para apostar por una aproximación imparcial, articulada y productiva.

Parte I:

"The Narrative Reloaded: Ficción, narrativa(s) y discursividad en la cultura del videojuego" 
La posmodernidad ha manifestado -y problematizado- de diversas formas la fragmentación identitaria de la subjetividad en la época del cambio de milenio. Esta ruptura del sujeto ha dado lugar a una multiplicidad ontológica que ha tenido un efecto actancial en los modos de representación contemporáneos, deviniendo en una "perturbación" crítica que cuestiona los fundamentos del pensamiento científico, y apuesta por la viabilidad de la contingencia como mecanismo de actuación (performance) identitaria.

En los últimos años, esta aporía descentralizadora del sujeto se ha venido manifestando de forma continuada en los varios campos de las artes: en literatura, conocidos son los rifirrafes estéticos de Paul Auster ${ }^{2}$ o Thomas Pynchon ${ }^{3}$ con la concepción moderna del sujeto; David Lynch $^{4}$, los hermanos Wachowski ${ }^{5}$ o -más recientemente- James Cameron ${ }^{6}$ aportan al ámbito fílmico los mismos parámetros deconstructivos de la identidad que Lost $^{7}$, Californication ${ }^{8}$ o The Office ${ }^{9}$ representan desde la pantalla televisiva. El ámbito de los videojuegos ya ha alcanzado un estatus de precursor en algunas de estas temáticas, y plantea una difusión de las fronteras ontológicas entre las diferentes proyecciones de la subjetividad que interactúan a ambos lados de la pantalla.

Second Life ${ }^{10}$, Grand Theft Auto ${ }^{11}$ y, recientemente, Heavy Rain ${ }^{12}-$ así como la mayoría de los juegos que pertenecen a la categoría de

2 William G. Little, "Nothing to Go On: Paul Auster's City of Glass". Contemporary Literature Vol. 38, No. 1 (Spring, 1997), pp. 133-163.

3 Marc W. Redfield. "Pynchon's Postmodern Sublime". PMLA, Vol. 104, No. 2 (Mar., 1989), pp. 152-162

4 Todd McGowan. "Finding Ourselves on a "Lost Highway": David Lynch's Lesson in Fantasy" Cinema Journal, Vol. 39, No. 2 (Winter, 2000), pp. 51-73

5 Bart Simon. "Introduction: Toward a Critique of Posthuman Futures" Cultural Critique, No. 53, Posthumanism (Winter, 2003), pp. 1-9

6 Ken Hillis. "From Capital to Karma: James Cameron's Avatar." Postmodern Culture 19.3 (2009) Project MUSE. Web. 18 Feb. 2011. <http://muse.jhu.edu/>.

7 O. S. Card, Getting Lost: Survival, Baggage, and Starting Over In J.J. Abrams' Lost. Dallas: BenBella Books, 2006.

8 Richard Huff. "David Duchovny sees the soul in his "Californication" character Hank Moody".Daily News, September 25th 2009. «http://www.nydailynews.com/entertainment/tv/2009/09/25/2009-0925 californication star david duchovny says his heel has a soul too.html? Acceso: 22 Mayo 2010.

9 Jeffrey Griffin, "The Americanization Of The Office: A Comparison Of the Offbeat NBC Sitcom and Its British Predecessor". Journal of Popular Film and Television 35.4 (2008): 154-163. Web. 18 Feb 2011.

10 Tom Boellstorff, Coming Of age In Second Life: An anthropologist Explores the Virtually Human. Princeton, N.J.: Princeton University Press, 2008. Print.

11 Nate Garrelts, The Meaning and Culture of Grand Theft Auto: Critical Essays. McFarland, 2006. Print.

Futhark 8 (2013)

ISSN 1886-9300 
"acción-aventura", y en particular de sandbox (narrativa no-lineal)- anticipan nuevas formas de escisión identitaria que se alejan de la centralidad propia del sujeto moderno para alojarse en la interactuación de multiplicidades como herramienta de proyección subjetiva, más propio de la posmodernidad. La relación existente entre quien maneja el mando y quien responde a éste deja de ser jerárquica y da paso a una reformulación narrativa en la que la perpetua reconstrucción de los personajes se yergue como episteme canalizador del sujeto fragmentado. Se trata de una "aniquilación del autor" como paso posterior a aquella "muerte del autor" reclamada por Barthes ${ }^{13}$, que queda sistematizada en el ámbito de la digitalización narrativa por el componente rizomático de la producción identitaria actual ${ }^{14}$. Desde esta posición, argumentamos que el ámbito del videojuego no sólo favorece, sino que también desestabiliza efectivamente los esquemas tradicionales del espacio narrativo.

"Narrative Reloaded": Entre los pensadores relacionados con el posmodernismo y el postestructuralismo, Roland Barthes trató de establecer una ruptura con los modelos cientificistas impuestos por el estructuralismo, y puso énfasis en el papel del lector y en la propia generación del significado. Emparentado con el pensamiento sostenido por Lyotard en La Condición Posmoderna ${ }^{15}$ de que las formas narrativas tienen una pluralidad y una heterogeneidad que no pueden ser resueltas recurriendo a una metanarrativa, Barthes afirma que lo que constituye una forma narrativa es inconmensurable para otra, y que esta relación se transmite también a la mantenida entre autor y lector, por lo que la generación de significados (y Homi Bhabha añadiría, y de identidades ${ }^{16}$ ) parte de las interacciones en conflicto entre esas dos entidades. Es importante, por lo tanto, entender que a la hora de referirnos a la narratividad que subyace en los videojuegos, se debe producir un distanciamiento de las concepciones tradicionales derivadas de la narratología y del estructuralismo, para adentrarnos en la aproximación posmoderna a las relaciones discursivas entre los diferentes participantes.

"Narrative Reloaded": La eclosión del videojuego como forma discursiva revela nuevas necesidades hermenéuticas a la hora de aproximarse críticamente a su sistematización. Pensemos como ejemplo comparativo en la conocida fotografía de Anthony Suau ("US Economy in Crisis",

12 J. Madison Davis, "Is Heavy Rain in the Forecast?", World Literature Today. Volume 84, Number 4 / July-August 2010.

13 Roland Barthes y Stephen Heath.Image, Music, Text. New York: Hill and Wang, 1978. Print.

14 Gilles Deleuze, Rhizome: Introduction. Les Éditions de Minuit, 1976. Print.

15 Jean-François Lyotard, The Postmodern Condition: A Report On Knowledge. University of Minnesota Press, 1984. Print.

16 Homi K Bhabha y Lisa Appignanesi, Identity: The Real Me. Institute of Contemporary Arts, 1987. Print.

Futhark 8 (2013)

Barros, Vídeo games Squared, 31-54

ISSN 1886-9300 
$2007^{17}$ ) en la que un policía de perfil se dispone a entrar, arma en mano, en una amenazadora sala que para el espectador de la fotografía permanece en absoluta oscuridad. Tal exposición de la escena repercute doblemente en el estado de inquietud de quien observa la imagen, ya que a la incertidumbre que genera el espacio desconocido al que se aproxima el agente armado, se une el desasosiego propio de quien no domina la escena, de quien ejerce como mero observador ajeno a la voluntad de los actantes. Tal identificación por parte del espectador con el sujeto de la imagen se multiplica exponencialmente en el ámbito del videojuego, ya que se pasa de esa incertidumbre por parte de la audiencia pasiva ante lo que espera a ese hombre armado en la habitación a la que se dirige, a que posean éstos la capacidad de decisión sobre las acciones de ese sujeto, cuya identidad es traspasada automáticamente a la del jugador. La experiencia narrativa, entonces, se multiplica de forma multidireccional, ya que el espectador/lector/jugador pasa de tener un papel exclusivamente activo en su pensamiento, a tener un papel activo también en la voluntad de los personajes. La narrativa se recarga, y adquiere multiplicidad ${ }^{18}$ actancial tanto por parte de los responsables del desarrollo del juego como por parte del propio jugador.

"Ficción, narrativa(s) y discursividad en la cultura del videojuego": Las fronteras interdiegéticas entre autor, lector y texto nunca han estado tan difuminadas como en el ámbito del videojuego. Cuando Jean Baudrillard habla del simulacro y la simulación en $1981^{19}$ ya está anticipando las relaciones que se producirán años después en el ámbito de la informática. La suspensión de la realidad para alcanzar formas de hiperrealidad se traslada también a la producción identitaria dentro del videojuego. El jugador, al adoptar el papel del personaje protagonista, realiza un proceso de identificación que plasma su producción ontológica en las características y acciones del personaje que maneja, con lo que la simulación (el juego) pasa a formar parte de la realidad actuada del jugador, mientras que su vida real queda en estado inerte, suspendida. La referencialidad $-\mathrm{y}$ la autorreferencialidad - se tornan en una suerte de estructura simulada de la realidad, una realidad con referencias pero sin referentes, alienada de aquello que tradicionalmente se ha dado a conocer como "mundo real".

Un acertado guiño a este supuesto teórico es el que se produce en el videojuego de 2003 Enter the Matrix, en el que se produce una parénte-

17 Ver 〈http://www.anthonysuau.com〉

18 Gilles Deleuze, Thousand Plateaus: Capitalism and Schizophrenia. Minneapolis: University of Minnesota Press, 1987.

19 Jean Baudrillard, Simulacra and Simulation. University of Michigan Press, 1994. Print.

Futhark 8 (2013)

Barros, Vídeo games Squared, 31-54

ISSN 1886-9300 
sis en la narración de la historia ya cerca del final para introducir una conversación entre dos avatares de los directores de la película que mantienen una conversación en la que hacen referencias directas a la persona que está manejando a través del juego a los personajes que ellos han creado. Con esta intervención autorial en la narrativa del videojuego, los autores parodian la necesidad inherente de un lector tradicional de poseer un referente real. El hecho de que no sean ellos quienes aparecen para protagonizar este paréntesis discursivo en la narrativa del juego, sino las proyecciones digitales de sus identidades, conlleva que la descontextualización de la narrativa no es sino una continuidad de ella, en la que el jugador participa doblemente: como proyección digital de su identidad a quienes se dirigen estos "avatares" dentro del juego, y como entes extrínsecos al juego que han ido a ver las películas de los hermanos Wachowski. Esta artimaña narrativa por parte de los directores del juego plantea la pregunta de si existe alguna diferencia entre esas dos identificaciones. Por el mero hecho de legitimar una pregunta de esta envergadura, ya se acepta al videojuego como artefacto cultural con una discursividad propia.

"Ficción, narrativa(s) y discursividad en la cultura del videojuego": Roland Barthes escribió en 1977 que la "narrativa es internacional, trans-histórica y transcultural: simplemente está ahí, como la vida misma" (67). Por eso, se han de entender las narrativas no como formas homogéneas y encasilladas en una determinada estructura, sino como entidades vivas en las que participan diversos agentes y factores que las moldean atendiendo a criterios temporales y espaciales, pero sobre todo contingentes. Tal y como ya argumentaba Jorge Luis Borges a mediados del siglo XX, no es lo mismo leer —o escribir- el Quijote en el siglo XVII que leerlo -o escribirlo- en el siglo $\mathrm{XX}^{20}$; así, tampoco es lo mismo jugar al mismo videojuego en el año 1985 y en el año 2010. Sus narrativas han cambiado, son narrativas otras que en el ámbito posmoderno trascienden su condición subalterna para proclamarse legítimas en su desarrollo. Los críticos actuales del ámbito de los Game Studies afirman que las teorías narrativas estándar ya no tienen validez para enfrentarse a las nuevas exigencias de los medios electrónicos, en particular a las de los videojuegos, y reclaman un nuevo paradigma teórico —al que denominan "ludología"- para referirse a una aproximación crítica que considere la distancia existente entre la narrativa y el videojuego, tal y como afirma Jan Simons en 200921. Tal afirmación puede ser contestada desde la misma teoría posmoderna, ya que los

20 Jorge Luis Borges, Ficciones. New York: Grove Press, 1962. Print.

21 Simons, Jan. "Narrative, Games, and Theory." Game Studies, 7.1 (agosto 2007).Web. 14 July 2010. 
ludólogos (Frasca o Aarseth) ${ }^{22}$ ofrecen una lectura reduccionista del concepto de narratividad, y lo ven como una entidad rígida. Nuestra lectura es que el campo de la ludología no se halla tan distante de la concepción posmoderna de la narrativa, cuya esencia se encuentra en la fragmentación paradigmática como mecanismo hermenéutico. El ámbito que nos permite trazar líneas de concomitancia entre una y otra aproximación es el espacial, en concreto, el rizomático, de cuya esencia emanan los formatos de multiplicidad.

Un rizoma es una (des)estructura sin centro que se multiplica en forma de red y que se aleja de las estructuras de pensamiento basadas en la modernidad y fundamentadas en la concepción arbórea, es decir, jerárquica y binaria del pensamiento. El ejemplo más claro de una estructura en rizoma es Internet, pero siguiendo a Deleuze (1987), no podemos restringir el pensamiento del rizoma como unidimensional, sino como una forma de multiplicidad que le es inherente a los mismos planos de conocimiento. En lo referido a los videojuegos y a la narratividad articulada en éstos, el componente espacial es, insisto, fundamental. Ya Foucault ${ }^{23}$ había hablado de las diferentes formas de heterotopías para referirse a esos espacios que existen en su simulación. Son, pero no son, como ocurre en el ejemplo tantas veces expuesto del espacio que se encuentra en un espejo. La representación de ese espacio reflejado ante nuestros ojos pertenece a un lugar híbrido en el que coexisten los discursos de representación y performance. Eso es la heterotopía: un espacio paralelo de otredad que no se halla ni aquí ni allá, y que es simultáneamente físico y mental. Otros reconocidos críticos como Marc Augé $^{24}$ cuando habla de los "no-lugares" o Edward Soja ${ }^{25}$ cuando se refiere a sus "third spaces" han desarrollado mucho más esta idea, pero para los intereses de este artículo conviene centrarse sólo en observar las repercusiones que tiene sobre la narratividad la creación de un espacio heterotópico a partir de los videojuegos. Dentro de la complejidad del concepto de heterotopía, podemos observar que el ámbito del videojuego tiene lugar para todas sus ramificaciones: heterotopías de crisis, de desviación, de tiempo, de purificación, de ilusión y de compensación,

22 Gonzalo Frasca, "Simulation versus Narrative: Introduction to Ludology". En Video/Game/Theory, editado por Mark J.P. Wolf y Bernard Perron. New York: Routledge, 2003 y Espen J. Aarseth, Cybertext: Perspectives on Ergodic Literature. Baltimore: The Johns Hopkins University Press, 1997

23 Foucault, Michel. "Des espaces autres".Dits et écrits II, 1976-1988. Paris: Gallimard, 2001.

24 Marc Augé, Los no lugares: Espacios del anonimato. Trad. Margarita Mizraji. Barcelona: Gedisa, 1992

25 Edward W. Soja, Thirdspace: Journeys to Los Angeles and Other Real-andImagined Places. New York: Wiley-Blackwell, 1996.

Futhark 8 (2013) Barros, Vídeo games Squared, 31-54

ISSN 1886-9300 
pero sobre todo, la heterotopía en el videojuego marca un espacio Otro para la narratividad presente en la historia. La fluctuación identitaria del jugador con su personaje no es más que una corriente alterna dialéctica que complementa las identidades mutuas mientras dura el juego [tal vez incluso después]. El receptor del mensaje se convierte en emisor y en mensaje a la vez, deconstruyendo así, de forma plástica, las instancias narrativas tradicionales, en lo que podría entenderse como una reescritura de la nívola de Unamuno aplicada a las nuevas tecnologías. El jugador construye una identidad para su personaje dentro de esa heterotopía narrativa, que a su vez repercute en el no-espacio del jugador visto desde su plasmación espacial en el videojuego.

En ese sentido, la realidad no puede ser concebida como un elemento Uno, sino como una continua fluctuación de eventualidades que dan lugar a la contingencia como marcador referencial del pensamiento en multiplicidad. Tal acción teórica se representa en el plano de aplicación en cómo los elementos fundamentales de la ludología, es decir, la simulación y el performance o la actancialidad conviven - aunque de forma problemática-con el elemento fundamental de la narratividad: el discurso.

"Ficción, narrativa(s) y discursividad en la cultura del videojuego": En torno a la discursividad como forma elemental de producción de identidades, en primer lugar hay que plantearse quién es capaz de realizar acciones en este espacio heterotópico. Desde luego, un sujeto. Pero, ¿qué es un sujeto? Si esta pregunta se le plantea a un pensador de la modernidad, probablemente será capaz de articular una respuesta muy diáfana. Pero si nos lo preguntamos en el ámbito de la era digital, la respuesta es más compleja (como ya se ha demostrado desde la eclosión del pensamiento posmoderno ${ }^{26}$ ). Podríamos empezar por afirmar que el sujeto es aquel ente que está en posesión de subjetividad, pero a esa imprecisa respuesta seguiría una nueva cuestión: ¿qué es la subjetividad? Kelly Oliver en el año $1998^{27}$ afirma que la ontología de la posmodernidad está definida por seres formados por subjetividades sin sujetos. No es del interés de este estudio entrar en profundidad a teorizar sobre la integridad del sujeto como refuerzo de la movilidad de las subjetividades, pero sí es importante señalar este pensamiento como una evolución lógica de lo que se ha dado a conocer en el ámbito de los Hypertext Studies como "la condición posthumana". En su estudio de 1999 How we became posthuman ${ }^{28}$, Katherine Hayles explica que las

26 Lyotard. 1984

27 Oliver, Kelly. Subjectivity Without Subjects. New York: Rowman \& Littlefield Publishers, Inc., 1998.

28 Hayles, N. Katherine. How We Became Posthuman: Virtual Bodies In Cybernetics, Literature, and Informatics. 1st ed. University Of Chicago Press, 1999.

Futhark 8 (2013)

Barros, Vídeo games Squared, 31-54

ISSN 1886-9300 
nuevas tecnologías han rediseñado definitivamente nuestra producción ontológica (en referencia a la subjetividad) y nuestra producción epistemológica (en referencia al conocimiento). En realidad, ambas son inseparables, y en el ámbito de la narrativa en el videojuego es donde mejor se puede observar esta producción discursiva como forma de producción identitaria.

Con esto se podría concluir esta primera parte del estudio afirmando que las nuevas maquinarias narrativas ofrecidas por el soporte digital de los videojuegos tienen una repercusión actancial que trasciende los límites de la narratividad contextual al discurso literario para apostar por una confluencia insoslayable entre la estética bidireccional del discurso comunicativo narrativo y la deontologización identitaria a la que se somete el sujeto sin subjetividad al sentarse frente a una pantalla y empuñar los mandos de un videojuego.

Parte II:

Historia y evolución de los videojuegos

\section{Introducción}

La historia de los videojuegos comenzó en 1972, y los pioneros fueron técnicos de Sillicon Valley, que abandonaron sus trabajos en busca de un sueño: el desarrollo de algún tipo de software que fuese atractivo para el gran público y al mismo tiempo divertido para ellos. Todo ocurre en el contexto de la llamada 'guerra fría' entre los EE.UU y la entonces denominada URSS. Estos desarrolladores, motivados por un alto interés personal por la diversión, y sin infraestructuras empresariales ni las finanzas de una empresa poderosa, ha sido la semiente de las modernas industrias de videojuegos que actualmente generan más resultados económicos que los propios estudios de Hollywood. (Vogel, 2007)

\section{El principio}

El primer juego, denominado PONG, simulación de un partido de tenis, se desarrolló a principios de los años setenta, por Nolan Bushnell, un técnico de Sillicon Valley, que creó una compañía llamada Atari, nombre derivado de un término japonés que significa 'voy a ganar' y que fue capaz de hacer creer a otro técnico, llamado Al Alcorn, que tenía un contrato con la empresa General Electrics para desarrollar la primera máquina llamada PONG. (Kent, 2001) Nolan no sólo convenció a Al Alcorn sino también al encargado de un bar, amigo suyo, para que le

Futhark 8 (2013)

Barros, Vídeo games Squared, 31-54

ISSN 1886-9300 
dejase instalar su invento en el establecimiento que éste regentaba, así los clientes podían jugar después de activar el juego con unas monedas. Aquella misma noche, ante la llamada del gerente, acudieron al local para solucionar una avería cuya solución consistió en reemplazar el peto por otro de mayor capacidad, ya que el primero se había llenado en un solo día.

En poco tiempo, las máquinas PONG aparecieron en bares y otros lugares. Atari se convirtió en una empresa prometedora que despegó rápidamente. Otro de sus ingenieros disminuyó el tamaño de la PONG para poder utilizarla en casa. Había nacido la primera consola. Pero antes había que resolver problemas jurídicos surgidos por la autoría del juego. Otro ingeniero llamado Baer la reclamaba. El acuerdo legal y monetario llegó al final, dejando la puerta abierta al desarrollo de la industria de juegos de Atari. Pronto descubrieron los técnicos de Atari y otros recién graduados el gran potencial económico de los videojuegos y se lanzaron a la creación de nuevos juegos y nuevas empresas. E resultado fue el nacimiento de una nueva industria -la industria del vídeo juego.

\section{Eclosión de Ideas}

Dado el éxito de los primeros juegos y el consecuente beneficio económico de las primeras empresas del sector, pronto surgieron nuevas iniciativas cuyo resultado fue irregular por la calidad de sus productos. En este contexto, la idea de los videojuegos ya se había extendido al continente europeo y fueron dos gemelos británicos a quienes sus padres habían comprado un ordenador para ayudarles con sus deberes, los que empezaron el desarrollo de juegos que compartirían con compañeros de clase. Uno de ellos, llamado 'Road Runner' —un conductor al que la carretera por la que conducía su coche se le iba estrechando cada vez más - resultó premiado por una revista. El premio otorgado promovió la creación de su propia empresa, denominada CodeMasters, hoy en día un referente para desarrolladores de videojuegos, y les vinculó contractualmente para el desarrollo de sucesivos trabajos para la misma revista. (Loquidice, et al., 2009)

En este contexto, surgieron títulos, actualmente reconocidos como clásicos, tales como 'Pitfall', 'Raiders Star' o 'Centipede'. Otros títulos que marcaron un punto de inflexión en la historia de los videojuegos fueron 'Asteroids', el primero en la utilización de gráficos vectoriales en todo el juego y 'Space Invaders' que consistía en la invasión de una horda de marcianos a quienes el jugador debería eliminar y por tanto impedir su aterrizaje sobre el fondo de la pantalla. El toque emotivo, y no previsto en el juego, lo proporcionaban algunos 'marcianos' más rápidos 
que otros y por tanto más imprevisibles. Fue tanto el beneficio económico de la compañía propietaria de este tipo de juegos en Japón que se agotaron las monedas de cien yenes y el gobierno se vio obligado a emitir más por la demanda de las mismas.

En pocos años, pues, la industria del videojuego se trasladó de EE.UU. a Japón donde visionarios tales como el joven Shigeru Miyamoto que trabajaba entonces en una empresa de divertimento tradicional llamada Nintendo que, a su vez, decidió unirse a la nueva industria en los años ochenta. Miyamoto reflexionó sobre su propia forma de juego en su etapa de niño y recuperó las historias de sus cuentos infantiles desarrollando, entre otras, la historia de un mono gigante -Donkey Kong-- que secuestraba a una princesa y era un niño, Jumpman, con bigote y ataviado con un sombrero, quien iba en su rescate, ambos efectos, bigote y sombrero, para dar solución a problemas técnicos con menos píxeles. Dos años más tarde, este niño se transformaría en el conocido Mario. Fue, no obstante, 'La leyenda de Zelda' que presentaba un mundo maravilloso de criaturas y aventuras con jóvenes jugando en un bosque cercano a la casa donde el autor había pasado su infancia, su obra maestra y lo que convirtió a Nintendo en la empresa de juegos más poderosa del momento en aquel momento. (Loquidice, B. et al., 2009)

\section{El juego compartido}

Algunos otros ingenieros como Will Crowther crearon aventuras en las que se podía elegir el camino a seguir, el destino del nuevo avatar y los objetos que éste portaba. Este nuevo concepto llamado MUD (Multi User Dungeon) permitía la conexión con otros equipos de juego y, de este modo, compartir las aventuras no sólo con amigos que se encontraban en el mismo espacio sino también en la misma ciudad, país o cualquier parte del mundo que tuviese conexión con el equipo servidor que generalmente se encontraba en universidades. Este nuevo concepto se considera el germen de lo que ahora se conoce como MMORPG (Massive Multiplayer Online Role Playing Game) aunque en su inicio se denominaban MUDs. (Flew, T. et al., 2005)

'Dungeons \& Dragons' fue el origen de muchos juegos llamados de rol aunque también ha habido otras influencias tales como de la serie ULTIMA que contribuyeron a la creación de aventuras que ocurrían en cavernas y mazmorras donde el protagonista andaba a la procura de demonios, monstruos y vampiros contra los que combatía con la esperanza de convertirse en más fuerte, conseguir algún preciado tesoro o simplemente elevar la moral de su personaje. 'Never Winter Night' (1991) fue el primer juego con interfaz gráfica, tal como se conoce hoy,

Futhark 8 (2013)

Barros, Vídeo games Squared, 31-54

ISSN 1886-9300 
cuyos protagonistas y personajes podían interactuar socialmente y además podía jugarse en la Red. Hoy en día, los juegos del tipo MMORPG son muy comunes y un título destacado 'World of Warcraft' nos traslada a un universo imaginario donde luchamos contra demonios, dragones y criaturas inmortales o incluso podemos convertirnos en personajes míticos del tipo de enanos, minotauros, o elfos para luchar juntos contra el bien o el mal. 'Second Life' también ha ejercido una influencia notable por su complejidad ya que permite representar una segunda vida virtual en la que se puede conseguir un trabajo, visitar museos, parques, ciudades reales representadas virtualmente, hablar con la gente, obtener dinero por medio de un trabajo o negocio virtual. Incluso se puede llegar a ser millonario o famoso virtualmente.

\section{Una nueva dimensión}

Con las crecientes exigencias de algunos juegos, y con el potencial de las nuevas tarjetas gráficas, los juegos se volvieron cada vez más complejos, hasta el punto de que tuvo que darse un nuevo paso hacia adelante. (Azuma, R. et al., 2001) Hasta este momento, los gráficos se representaban en dos dimensiones (altura y anchura), pero se añadió una nueva dimensión, la de profundidad. Los videojuegos se convirtieron en algo grandioso.

Es necesario, no obstante, hacer notar aquí que el primer juego en 3D es más antiguo de lo que se cree. (Fernández-Vara, et al., 2005) 'Monster 3D Maze' se desarrolló en 1982 para Sinclair ZX-81, el equipo más común entonces, conectado a un televisor. Fue un paso de gigante para los equipos domésticos. Ese juego consistía en un laberinto en el que algunas criaturas prehistóricas nos acechaban desde cualquier esquina, y había que huir de ellas para evitarlas.

En el mismo año nació el '3-Demon', una versión del conocido 'Pacman'. Pero con la característica de que todo el juego era en primera persona. 'The Dungeons of Dagorath' ocurría en unas mazmorras y todos los personajes se dibujaron en gráficos vectoriales que se construyen por medio de fórmulas matemáticas en vez de mapas de bits y ofrecen más flexibilidad para el juego.

3D proporcionaba una visión del mundo virtual como no se había hecho antes. Una realidad más cercana a la nuestra. Los ejemplos desarrollados con esta tecnología se denominaron en principio juegos $2.5 \mathrm{D}$ o de perspectiva isométrica y utilizaban técnicas para representar la profundidad. En el caso de 2.5D se utilizaba una imagen móvil en el fondo con velocidad diferente a la capa más cercana. Ejemplos de esta tecnología podría ser 'Street Fighter' o ‘Out Run'. 
En el caso de las técnicas de perspectiva isométrica, en lugar de representar el juego en unidades cuadradas, se representaba en unidades de forma de diamante, lo cual proporciona una visión profunda de cada acción. Esta técnica fue muy común en los juegos de estrategia, ya que permitía un mayor número de elementos en pantalla, sin dificultar su visión; ejemplo de ello fue la serie 'Command \& Conquer', 'Sim City' y también el mejor juego español de la historia 'Abadía del crimen', basado en la novela de Umberto Eco, El nombre de la rosa.

Los juegos que realmente hicieron por primera vez uso de la tecnología de gráficos 3D fueron 'Starfox', 'Wolfestein 3D' o 'VirtualRacing'. En poco tiempo, los juegos más solicitados se creaban con estos polígonos y consecuentemente demandaban cada vez más recursos de los lentos ordenadores domésticos. Las estadísticas prueban que la demanda de tales recursos aceleró el desarrollo de los procesadores gráficos, la velocidad de memoria y el desarrollo de buses por parte de los fabricantes de hardware de los ordenadores.

\section{Mundo Real Vs. Mundo Virtual}

Con la nueva tecnología 3D los juegos cambiaron en muchos aspectos, especialmente en la forma de representación de las escenas puesto que hay momentos en los que es difícil distinguir entre lo real o lo ficticio, entre una fotografía o una infografía. 'Myst', desarrollado totalmente en 3D, incluía personajes representados por actores reales lo cual permite que la interacción sea mucho más compleja.

Esta tecnología basada en polígonos, combinados entre sí, permite la formación de imágenes tales como barcos, espadas, creaturas o personajes que muestran todo tipo de detalles y se mueven por los escenarios de forma natural. En 'Alone in the Dark', la cabeza del personaje principal estaba formada por un globo, el cuerpo por una caja, los brazos y las piernas por cilindros. Actualmente, motores gráficos programas que renderizan las imágenes-- tales como Unreal Engine 3 o CryEngine permiten crean mundos en los que es muy difícil distinguir lo real de lo virtual.

Otro aspecto que debemos considerar en los videojuegos actuales es la inclusión de personajes homéricos que son capaces de realizar acciones propias de semidioses o titanes ya sea por su gran fortaleza física o por su propia naturaleza y escenarios en los que ocurre la acción. En 'FallOut 3' el personaje principal es un superviviente de una guerra nuclear entre China y los EE.UU. Washington se ha convertido en una tierra deshabitada llena de criaturas mutantes debido a la radiación existente. 'Crysis' rememora una guerra al estilo de Vietnam cuya

Futhark 8 (2013)

Barros, Vídeo games Squared, 31-54

ISSN 1886-9300 
acción ocurre en la jungla donde se pueden palpar las hojas que caen de los árboles sujetas a las más férreas leyes de la física. Algunos juegos han llegado a emplearse como instrumentos simuladores de tareas especiales. 'America's Army' se ha utilizado como simulador de combate real para entrenamiento de los soldados y prácticas de tácticas de guerra.

La posibilidad de recrear la realidad o incluso de mejorarla añade un componente de atracción para los seres humanos quienes, de esta manera, pueden proyectar sus deseos y ambiciones sobre sus avatares y así ser capaces de vivir aventuras y situaciones imposibles en un mundo real. 'Jekyll and Hyde' ofrecen la oportunidad de experimentar este tipo de sensaciones.

\section{Bienvenido al mundo virtual}

A principios de los años noventa las palabras 'mundo virtual' inundaron todas las películas de la década. 'The Lawnmower Man' basada en un hombre, deficiente mental, y con una máquina que lo introduce en un mundo virtual, obtiene así mejores resultados en su coeficiente intelectual y adquiere poderes similares a los de un dios en la tierra. Otro ejemplo es "Johnny Mnemonic", un hombre con un disco duro en su cerebro y que utiliza un mundo virtual para ver los datos contenidos en el disco.

'Mundo virtual', en el caso de los videojuegos, se refiere al lugar o entorno en el que viven y actúan personajes. Algunos de estos mundos pueden estar llenos de vida tal es el caso de 'FallOut3' o 'Oblivion' en los que se pueden ver a animales alimentarse, o el bullicio de una ciudad. En otros juegos 'Command \& Conquer', 'Age of Empires', 'Diablo' esa vida artificial no es tan importante y lo relevante son los protagonistas que interactúan. En la actualidad el término 'mundo virtual' se aplica también a lo conocido como 'Realidad Aumentada', el mundo real modificado.

\section{La modificación del mundo real}

Al igual que todas las tecnologías, la Realidad Aumentada se utilizó en primer lugar para usos militares e investigación. La primera aparición de estos términos fue en 1992, referidos a una evolución del mundo virtual. (Poole, S., 2004) La tecnología de la Realidad Aumentada es una evolución de la Realidad Virtual en la que era necesario el uso de gafas especiales y lo que se veía era creado por un ordenador, pero en la Realidad Aumentada, se ve el mundo real con algunas modificaciones, tales 
como la información o la sustitución de elementos reales por los elementos que se crean con un ordenador. (Kato, H. et al., 1999) El equipo deberá distinguir algún tipo de marcas del mundo real para saber dónde están los elementos virtuales. Al igual que la vieja tecnología de los códigos de barras, pero que distingue la parte superior de la inferior de los objetos. De este modo, al visualizar un papel con un elemento virtual se podrán ver objetos tales como criaturas o muebles que el equipo haya puesto en dicho papel.

Desde 1992 las tecnologías han mejorado y se han podido trasladar al mundo de los teléfonos móviles, así Google la ha incorporado a sus teléfonos con el nombre de G1.

Hoy en día, en algunos juegos se hace uso de esta tecnología para interactuar con el jugador. 'The Eye of Judgment' es un juego de cartas en el que se puede jugar a solas con el ordenador y con cartas reales. Además, se puede ver la batalla de esta cartas con criaturas en $3 \mathrm{D}$ y cómo dichas cartas interactúan con éstas.

El traslado de esta tecnología al mundo de la telefonía móvil implica, por ejemplo, que se podrá ver el menú de un restaurante sin entrar en él, conocer información sobre cualquier monumento con sólo enfocarlo con su móvil, incluso conocer el perfil de Facebook de cualquier persona o quién habita en una determinada casa. No queremos entrar en las consideraciones morales que todo esto conlleva, pero puede llegar a ser preocupante en manos de personas sin escrúpulos.

\section{El Project Natal}

Microsoft ha sorprendido al mundo del videojuego en la feria E3 de Los Ángeles. Su nuevo 'Project Natal' ha captado la atención al presentar una nueva consola que interactúa de forma distinta con el usuario.

Proyecto Natal se presenta como un complemento para la Xbox, que con una cámara especial es capaz de captar el movimiento de los jugadores sin ningún artilugio o hardware extra. El sistema, en el que Microsoft ha trabajado más de dos años y que se ha comercializado recientemente, va más allá del movimiento en cuanto que incorpora reconocimiento de rasgos físicos faciales, permite el escaneo e incorporación de objetos reales en los videojuegos, también incluye reconocimiento de la voz humana de modo que se puede conversar con los personajes del juego, dar órdenes con la voz e incluso permite elegir el modelo de vestido y probarlo virtualmente. (Chetty, 2009)

Todos estos avances deberán contar con la aceptación del público que es quién decide su incorporación al salón del hogar. En cualquier

Futhark 8 (2013)

Barros, Vídeo games Squared, 31-54

ISSN 1886-9300 
caso, este mundo resulta prometedor y cambia la forma de interactuar con la tecnología.

\section{El futuro que viene}

Hace varios años, sólo algunos visionarios podrían haber imaginado lo que hoy en día hemos incorporado a nuestra vida diaria: la comunicación instantánea a través del correo o la videoconferencia, las redes sociales de cuya influencia empezamos a ser conscientes, la televisión a la carta, los juegos en línea.

La tecnología se ha ido desarrollando en paralelo con la invención intelectual y en el caso de los juegos, la necesidad de dar vida a los personajes y el deseo de crear mundos en los que estos avatares se moviesen con soltura ha forzado el desarrollo del hardware que, de otro modo, sin duda alguna, habría ido o más lento o por otros derroteros. El hardware sigue disminuyendo de tamaño y en esta dirección algunas empresas están explorando nuevos caminos, así Sony está investigando sobre una lente de contacto como monitor de tipo OLED (Organic Light Emitting Diode) que permite una gran calidad de imagen en pantallas flexibles y podría emplearse en el futuro en tejidos o cualquier otro material.

Todos estos factores: la gran capacidad de almacenamiento, el poder de computación a pesar de la miniaturización de los ordenadores, la alta resolución de las pantallas, la gran capacidad de procesamiento gráfico, el uso compartido de los propios ordenadores llamado Cloud Computing junto con la inteligencia humana, nos permitirá el diseño y el desarrollo de nuevas y más prácticas aplicaciones para el entretenimiento, la enseñanza, la investigación, la ingeniería, la medicina, la representación gráfica, y otros campos de la actividad humana hasta ahora sólo imaginadas por algunos iluminados.

\section{Parte III: Juegos serios}

El pasado mes de septiembre de 2010, el presidente Barack Obama presentó ante la prensa de su país la organización Change the Equation ("Cambia la ecuación"). Fundada por pesos pesados de la industria tecnológica estadounidense, Change the Equation cuenta entre sus socios con más de cien presidentes de grandes corporaciones del país. La organización está enmarcada en el programa Educate to Innovate ("Educar para innovar") y tiene como objetivo corregir la situación descubierta en el informe PISA de 2006, en el que los estudiantes estadou- 
nidenses quedaban en 21 posición (de los 30 países más desarrollados) en ciencia y matemáticas.

En último término, el programa pretende incentivar el aprendizaje de las nuevas tecnologías y de las matemáticas en Estados Unidos para que el país pueda seguir siendo líder en el campo del I+D y de la innovación. La gran novedad es que este programa busca llegar a los jóvenes a través de un conjunto de herramientas innovadoras conocidas como new form of media "nuevas formas de medios de comunicación" o alternative media "medios de comunicación alternativos", entre los cuales el videojuego ocupa un puesto destacado:

America is already stepping forward to meet these challenges. As part of the "Educate to Innovate" effort, five major public-private partnerships are harnessing the power of media, interactive games, hands-on learning, and community volunteers to reach millions of students over the next four years, inspiring them to be the next generation of inventors and innovators (Educate to Innovate).

La inclusión de los videojuegos en este macroprograma es muy significativa y muestra la importancia que los mismos están adquiriendo como potente herramienta educativa. Educate to Innovate tiene además una secuela en la empresa privada, con el patrocinio que Microsoft ha hecho de un proyecto del Massachussets Institute of Technology (MIT) para explorar las posibilidades del videojuego en el terreno de la enseñanza.

\section{Los juegos serios: origen y naturaleza}

Hoy por hoy se ha escrito ya una buena cantidad de literatura acerca de los videojuegos en la educación. En un primer momento, la investigación en este terreno se centró fundamentalmente en dos cuestiones. En primer lugar, la justificación que el uso del videojuego puede tener en el marco de un proceso de enseñanza-aprendizaje, sus aplicaciones y su puesta en práctica en un aula. Y en segundo, la clasificación de los videojuegos atendiendo a criterios pedagógicos, técnicos o de estructura narrativa.

Una de las propuestas de clasificación es la presentada por Anne Derryberry atendiendo a su finalidad y su naturaleza. Según Derryberry, los videojuegos pueden ser casual games ("juegos ocasionales") si se trata de juegos intrascendentes, fáciles de manejar y sin una estructura narrativa compleja. Son juegos ocasionales muy conocidos el Tetris, el Solitario o el Póker, que suelen ofrecerse preinstalados en los sistemas operativos de PCs y dispositivos electrónicos para entretenimiento ocasional. En el extremo contrario sitúa Derryberry los juegos que denomina core games, que podríamos traducir como "juegos comunes" o "juegos

Futhark 8 (2013)

Barros, Vídeo games Squared, 31-54

ISSN 1886-9300 
básicos". Se trata de los videojuegos clásicos o paradigmáticos, que se caracterizan por su intensidad, su duración y continuidad en el tiempo, su complejidad de manejo y su estructura narrativa elaborada.

Ambos pivotan sobre el concepto de entretenimiento, que es su objetivo principal, aunque esto no quiere decir que estos juegos no puedan ser vehículo de conocimiento o incluso ser aprovechados con alguna finalidad pedagógica en educación. Sin embargo, Derryberry opone ambas categorías de videojuegos a una tercera, que denomina serious games "juegos serios" y que se distinguen de los anteriores porque han sido diseñados con alguna finalidad adicional a la del puro entretenimiento:

Serious games are designed with the intention of improving some specific aspect of learning, and players come to serious games with that expectation. Serious games are used in emergency services training, in military training, in corporate education, in health care, and in many other sectors of society. They can also be found at every level of education, at all kinds of schools and universities around the world (3).

Los juegos serios, que también se conocen con los nombres de immersive learning simulations "simulaciones de aprendizaje por inmersión", digital game-based learning "aprendizaje digital basado en el juego", o gaming simulations "simulaciones de juego", se basan en los principios de learn by doing "aprender haciendo" y de team building "construcción de equipo". Es un hecho que casi todos los videojuegos -serios o nosuelen crear comunidades virtuales en las que se intercambia información y experiencias y en las que se produce, por tanto, aprendizaje.

El término serious games tiene su origen en el Departamento de Defensa de los EEUU, en donde se utilizó por primera vez para referirse en el Congreso a las simulaciones de guerra que utilizan para seleccionar y entrenar a sus soldados. La aplicación se llama America's Army ${ }^{29}$ y surgió como una respuesta a la carencia de vocación militar y tras varias macro campañas publicitarias fracasadas. Actualmente la aplicación tiene 8 millones de cuentas activas y ha generado comunidades virtuales con más de 700.000 usuarios.

Otro de los pioneros en el terreno profesional fue el Flight Simulator, de Microsoft ${ }^{30}$, que salió a la venta en 1982 y que utilizan los pilotos para entrenarse. McDonald's también se sirve de un juego serio para entrenar a su personal de tienda en materia de atención al consumidor, trabajo en tienda y supervisión de empleados. En la aplicación el jugador adopta el papel de camarero en el McDonald's teniendo que enfrentarse a distintas situaciones, como conflictos con un cliente, etc. La aplicación

29 http://www.americasarmy.com/

30 http://www.microsoft.com/games/flightsimulatorx/

Futhark 8 (2013)

Barros, Vídeo games Squared, 31-54

ISSN 1886-9300 
va ofreciendo distintas opciones de resolución entre las que el empleado tiene que ir eligiendo.

\section{Tipos de juegos serios}

Pero Derryberry va más allá en su clasificación de los videojuegos al establecer tres tipos de juegos serios. Distingue Derryberry entre los juegos propiamente educativos o educational games, los exergames (de exercise y game) "ejerjuegos" (aquellos que exigen algún tipo de ejercicio físico como pedalear o dar puñetazos, de los que la consola Wii es paradigmática) y propaganda games "juegos de propaganda", que tienen como finalidad ejercer una influencia en el pensamiento de los jugadores (difusión de ideas, ideología, etc.) Una variante de los juegos de propaganda, según Derryberry, son los newsgames o "juegos de noticias", que se crean a la sombra de un acontecimiento muy reciente con el objetivo de generar un debate sobre el mismo. Un buen ejemplo de estos juegos sería Darfur is Dying ${ }^{31}$.

Derryberry especifica en su artículo que no entran en la categoría de juegos educativos programas como tutores de mecanografía o aplicaciones para aprender idiomas, que M. J. Dondlinger denomina edutainment "edutenimiento" (de "education" y "entertainment"). Si el edutenimiento se caracteriza según Dondlinger por tener una progresión lineal, sin alternativas ni interactividad, los juegos educativos exigen en cambio probar hipótesis, estrategia y resolución de problemas y suelen presentar un reto, un contexto narrativo y una dificultad creciente:

Edutainment games, then, are those which follow a skill and drill format in which players either practice repetitive skills or rehearse memorized facts. (...) In contrast, educational video games require strategizing, hypothesis testing, or problem-solving, usually with higher order thinking rather than rote memorization or simple comprehension (2).

\section{Videojuegos y enseñanza de lenguas modernas}

Como ya hemos dicho, los expertos llevan tiempo preguntándose si los videojuegos son verdaderamente eficaces en educación. Mucho se ha avanzado, particularmente, en el terreno de la enseñanza de lenguas modernas, hasta el punto que existen ya en el mercado un buen número de juegos para desarrollar la competencia comunicativa en lengua ingle-

31 http://www.darfurisdying.com/

Futhark 8 (2013)

Barros, Vídeo games Squared, 31-54

ISSN 1886-9300 
sa. Si bien es cierto que la mayoría de esas aplicaciones estarían en la categoría de edutenimiento tal y como fue definida por Dondlinger, ya hay algunos videojuegos propiamente educativos en el mercado.

Muchos profesores de lenguas modernas y pedagogos insisten en la idea de que es importante incluir en las programaciones didácticas contenidos de naturaleza audiovisual argumentando que vivimos en la cultura de la imagen y que, por tanto, su uso en el aula contribuye a acercar los contenidos al mundo real aumentando la motivación del alumnado. En esta línea, Derryberry estudia el impacto del videojuego en la motivación, que define como la suma de deseo más placer. Concluye Derryberry que la narrativa del videojuego es responsable de la mayor parte de la motivación, que se ve incrementada aún más por la perspectiva de primera persona a través del uso de un avatar por parte del jugador.

De acuerdo con Derryberry los juegos tienen la capacidad de colocar al aprendiz-jugador en un contexto real e integrarlo en una comunidad de práctica. Contribuyen a desarrollar la atención, concentración espacial, resolución de problemas, toma de decisiones, trabajo colaborativo, creatividad y habilidades con las TICs. Sin embargo, la mayoría de los profesores de lenguas modernas no saben qué hacer o cómo sacar partido de esas herramientas.

El uso de videojuegos en clase de lengua moderna se puede abordar de tres maneras diferentes: buscando aplicación a un videojuego de tipo común u ocasional ya existente en el mercado y elaborando una explotación pedagógica específica; introduciendo en la programación el uso de un juego serio específicamente creado para enseñar lo que se quiere (ya sea de tipo educativo o de edutenimiento), o desarrollando un videojuego específico (ya existen herramientas en el mercado que permiten hacer esto).

En cualquiera de los tres casos, el uso del videojuego en el aula debería intentar responder al desarrollo de una o varias de las competencias comunicativas tal y como estas están definidas en el Marco Común Europeo de Referencia para las Lenguas (MCERL) en una o varias de las cuatro destrezas comunicativas: expresión y comprensión orales y escritas. Además, idealmente, su puesta en práctica debería servir a una o varias funciones comunicativas propias del nivel de enseñanza de que se trate; funciones como invitar, disculparse, presentarse, comprar, describir, etc.

Cualquier videojuego en la lengua objeto puede ser fácilmente explotado en las destrezas de comprensión oral y escrita, dado que la mayoría de ellos incluyen textos, diálogos y narraciones. Pero también son cada vez más frecuentes los videojuegos con motores de reconocimiento de voz, en los que el jugador tiene que dar instrucciones orales por 
medio de un micrófono, cuyo aprovechamiento en el terreno de la expresión oral puede llegar a ser muy productivo.

Dentro de la competencia lingüística, el rendimiento de un videojuego será muy elevado en el terreno de la ortografía, la gramática y el léxico, especialmente en los campos semánticos utilizados en el universo narrativo propuesto por el juego. Pero también en la competencia sociolingüística se puede sacar partido de un videojuego bien explotado, particularmente en lo concerniente a marcadores de relaciones sociales y diferencias de registro, dialecto y acento.

\section{El videojuego en el aula}

La inclusión de un videojuego en el marco de una programación didáctica puede conllevar una serie de dificultades que el docente deberá solventar y que serán diferentes según el contexto educativo en el que trabaje. Una de las variables determinantes es la competencia tecnológica del alumnado, que con seguridad será más alta en Enseñanza Secundaria o en Enseñanza Universitaria que en otro tipo de educación para adultos, como la Escuela Oficial de Idiomas, en donde puede haber gente sin alfabetizar en TICs y que, por tanto, podría tener problemas para manejarse con un videojuego. Otro factor determinante es la disponibilidad de equipos informáticos suficientes en el centro educativo y su capacidad para gestionar videojuegos de última generación, que suelen ser muy exigentes en términos de rendimiento de hardware.

Finalmente, el docente deberá enfrentarse a la elección de un videojuego apropiado a las necesidades específicas del tramo educativo de que se trate, que no resulta nada sencillo. Como ya hemos dicho, la mayor parte de los juegos serios disponibles para enseñanza de lenguas son en realidad edutenimiento con gramática y ejercicios de vocabulario. Más raros son los juegos serios propiamente educativos. Por ello, lo más asequible es la adaptación de un videojuego no educativo a nuestras necesidades pedagógicas.

En este caso, lo más asequible es recurrir a la importación de un videojuego del país en el que se habla la lengua objeto, dado que en España es muy difícil conseguir videojuegos en lenguas distintas del castellano. Incluso los juegos que incluyen la opción multilenguaje (que son una minoría) no suelen especificar esta condición en la carátula, complicando sobremanera la búsqueda. Para solucionar este problema, cabría la posibilidad de buscar esta información en foros específicos, como El otro lado ${ }^{32}$. También existe una organización británica llamada Teachers

32 http://www.elotrolado.net/

Futhark 8 (2013)

Barros, Vídeo games Squared, 31-54

ISSN 1886-9300 
Evaluating Educational Media (TEEM) "Profesores Evaluadores de Multimedia Educativo" cuyo trabajo, difundido a través de su sitio web ${ }^{33}$, puede ayudar al docente a tomar una decisión en este terreno.

En el caso concreto de la enseñanza del inglés, el juego Play English ${ }^{34}$ para PSP, de la desarrolladora española Tonika, constituye toda una referencia en materia de juegos serios de tipo educativo. Los videojuegos de karaoke, como el conocido Singstar ${ }^{35}$ también pueden utilizarse para trabajar la competencia fonológica. En Football Manager ${ }^{36}$ el jugador-alumno tiene que ponerse en la piel del gerente de un equipo de fútbol y dar órdenes a los colaboradores y a los jugadores para gestionar el juego y el equipo; puede funcionar bien para desarrollar las competencias léxica y gramatical.

Socom ${ }^{37}$, de Play Station, se destaca por ofrecer la posibilidad de dar instrucciones orales, lo cual obliga al jugador-alumno a generar enunciados correctamente construidos y pronunciados si quiere continuar jugando. Todo apunta a que habrá cada vez más videojuegos con esta tecnología en el mercado, aunque su inconveniente es lo exigentes que estos son en términos de recursos informáticos.

En una sociedad en la que la información se transmite cada vez más por vía informática y audiovisual, los formadores deben hacer un esfuerzo por intentar incorporar esos instrumentos a sus programaciones didácticas en mayor o menor medida. Desde luego, estos no han venido a sustituir a las herramientas convencionales, pero sí para apoyarlas como un valor añadido contribuyendo a aumentar el nivel de motivación del alumno y a acercar la educación al mundo real y a la sociedad tal y como es hoy en día. Y en este proceso de enriquecimiento el videojuego tendrá sin duda un papel de gran importancia.

\section{Obras Citadas:}

AZUMA, R. et al. "Recent advances in augmented reality". Computer Graphics and Applications, IEEE 6 (34 - 47).

CHETTY, Vasu. Microsoft's Project Natal for Xbox 360. GearLive.com, 2009. Acceso 24 Feb 2011: <http://www.suite101.com/content/microsofts-projectnatal-for-xbox-360-a129412\#ixzz1ExaOfjs2>.

33 http://www.teem.org.uk/

34 http://es.playstation.com/psp/games/detail/item275177/

PlayEnglish\%E2\%84\%A2/

35 http://www.singstargame.com

36 http://www.entrenadordefutbol.es/

37 http://www.socom.com/

Futhark 8 (2013)

Barros, Vídeo games Squared, 31-54

ISSN 1886-9300 
DERRYBERRY, A. "Serious games: Online Games for Learning", 2007. Acceso 24 Feb $2011 \quad<$ <ttp://www.adobe.com/ resources/elearning/pdfs/serious_games_wp.pdf>.

DONDLINGER, M.J. "Educational Video Game Design: A Review of the Literature." Journal of Applied Educational Technology 4.1 (21-31): 2007.

FERNÁNDEZ-VARA, Clara et al. "Evolution of Spatial Configurations in Videogames". Actas de la DiGRA 2005 Conference: Changing Views - Worlds in Play, 2005. Acceso Feb 2011 $<$ http://citeseerx.ist.psu.edu/viewdoc/download?doi=10.1.1.67.97\&rep=rep1\&t ype $=$ pdf $>$.

FLEW, T. "Games: technology, industry, culture" en New Media: an Introduction. South Melbourne, Vic.: Oxford University Press, 2005 (101-114).

KATO, H. Y BILLINGHURST, M. "Marker Tracking and hmd Calibration for a VideoBased Augmented Reality Conferencing System", en Proceedings of the 2nd IEEE and ACM International Workshop on Augmented Reality (IWAR 99). Washington, DC, USA:IEEE Computer Society,1999.

KENT, Steve L. The Ultimate History of Videogames: From Pong to Pokemon and Beyond - The Story behind the Craze that Touched our Lives and Changed the World. New York: Three Rivers Pr., 2001.

LOGUIDICE, Bill y BARTON, Matt. Vintage Games: An Insider Look at the History of Grand Theft Auto, Super Mario, and the Most Influential Games of All Time. Boston: Focal/ Elsevier, MA, 2009.

POOLE, Steven. Trigger Happy: Videogames and the Entertainment Revolution. New York: Arcade Publishing, 2004

The White House. Educate to Innovate. Video. 20 feb 2011 <http://www.whitehouse. gov/issues/education/educate-innovate>

VoGEL, Harold L. Entertainment industry economics: A guide for financial analysis (7th Edition). Cambridge, Cambridge University Press, 2007

WINTER, David (1996-2010) Magnavox Odyssey. Acceso 24 Feb 2011 $<$ http://www.pong-story.com/odyssey.htm>.

Futhark 8 (2013)

Barros, Vídeo games Squared, 31-54

ISSN 1886-9300 